E3S Web of Conferences 1, 38003 (2013)

DOI: $10.1051 / \mathrm{e} 3$ sconf/20130138003

(C) Owned by the authors, published by EDP Sciences, 2013

\title{
Emissions, air concentrations and atmospheric depositions of arsenic, cadmium, lead and nickel in Italy in the last two decades: A review of recent trends in relation to policy strategies adopted locally, regionally and globally
}

\author{
M. Strincone ${ }^{1}$, A. Fino ${ }^{2}$, G. Cattani ${ }^{3}$, M. Catrambone ${ }^{4}$ and N. Pirrone ${ }^{5}$ \\ ${ }^{1}$ CNR-Institute of Atmospheric Pollution Research, Italy, strincone@iiia.cnr.it \\ ${ }^{2}$ CNR-Institute of Atmospheric Pollution Research, Italy, fino@iia.cnr.it \\ 3 ISPRA, Italian National Institute for Environmental Protection and Research, Italy, giorgio.cattani@isprambiente.it \\ ${ }^{4}$ CNR-Institute of Atmospheric Pollution Research, Italy, catrambone@iia.cnr.it \\ ${ }^{5}$ Director of CNR-Institute of Atmospheric Pollution Research, Italy, pirrone@,iia.cnr.it
}

\begin{abstract}
Heavy metals can cause adverse effects to humans, animals and ecosystems due to their bioavailability and toxicity in various environmental compartments. In the last decades, many policy strategies and measures have been taken at global, regional and local level in relation to heavy metals, due to their adverse effects and ability to be transported over long distances. Several EU measures have been adopted in order to control the pollution from heavy metals in the main sectors. This paper will provide an overview of trends of emissions, air concentrations and atmospheric depositions of heavy metals in Italy and of the main relevant EU legislation and its goals (Directives on paints, batteries, industrial emissions, etc.) together with policies adopted at Italian level.
\end{abstract}

Key words: Heavy metals, atmospheric pollution, air emissions reduction, heavy metal policies.

\section{Introduction}

According to the international scientific literature, heavy metals can cause adverse effects to humans, animals and ecosystems due to their bioavailability and toxicity in various environmental compartments. In the last decades, many policy strategies and measures have been taken at global, regional and local level in relation to heavy metals, in particular cadmium and lead, due to their adverse effects and ability to be transported long distances.

The first international legally binding instrument to deal with problems of air pollution on a broad regional basis is represented by the 1979 Geneva Convention on Long Range Transboundary Air Pollution (LRTAP), which has been extended by eight specific protocols. Following this treaty, further measures have been adopted both at regional level, for example the European Union strategies on air quality, mercury and waste treatment, and at global level, for example the discussion in progress under the UNEP umbrella dealing with lead and cadmium pollution.

\section{Emissions in Italy and in Europe}

Lead and cadmium occur in the environment as a result of both natural releases and releases associated with human activities.

The major natural emissions of lead come from volcanoes, airborne soil particles, sea spray, biogenic material and forest fires, while the major anthropogenic contribution to emissions is due to the extraction of metal residues and of other minerals like coal and lime, industrial activities, smelters and metal/oil refineries (UNEP,2010a).

The main sources of cadmium anthropogenic contamination is associated with mining, metallurgical industries, the use of fertilizers containing phosphates from mineral products, of paint and coating industries and electroplating industries (UNEP,2010a).

In Europe major anthropogenic sources of nickel are stationary combustion (55\%) and mobile sources and machinery other than road transport (30\%). With a view to air quality the relevant sources are petroleum refining and fugitive emissions from the electric arc furnace steel works. Important natural sources of nickel are windblown 
soil and volcanoes. Anthropogenic sources considerably outweigh natural sources. In Europe $86 \%$ of total arsenic emissions in the in 1990 was emitted by stationary combustion. However, in general the emissions from this sector do not result in relevant ambient air concentrations as they are released via sufficiently high stacks.. In general anthropogenic sources outweigh natural sources; the global natural share is estimated at $25 \%$, mainly from volcanoes. On a local scale there may be more significant contributions up to $60 \%$ from weathering processes in regions rich in sulphidic ore deposits (European Commission, 2003).

Emissions in Italy can be evaluated considering the data reported under the relevant EU regulations and the UNECE Protocol on heavy metals under the Convention on long range transboundary air pollution.

In particular the emissions into air and water from the major industrial plants are listed under the EPER Register, replaced by the E-PRTR register from 2007.

The UNECE Protocol on heavy metals foresees that Each Party shall develop and maintain emission inventories for several heavy metals, including lead, cadmium, arsenic and nickel. Italy has submitted the time series from 1990 to 2010 to the Convention Secretariat (ISPRA).

At national level, the Italian Institute of Statistics reports on heavy metals emissions from specific sectors for the period 1990-2007 (ISTAT).

According to the available data, the main emitting sectors for cadmium and lead include power production, waste treatment and manufacturing activities, with particular reference to the production of metals, metal products, non metal minerals and chemicals.
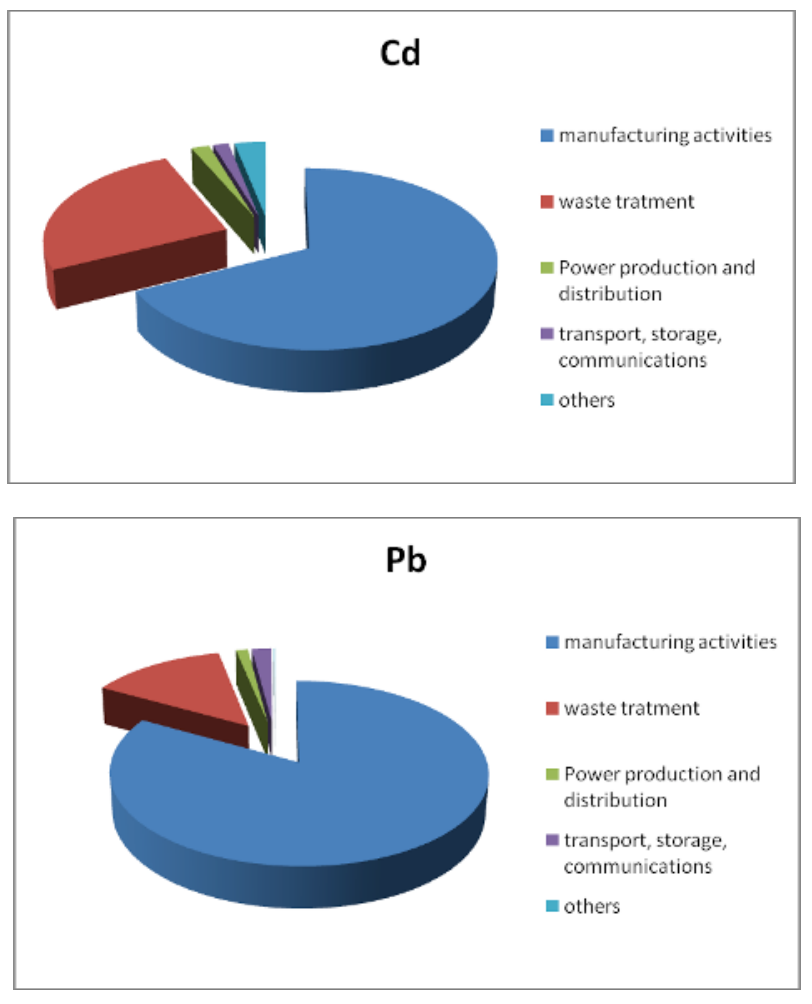
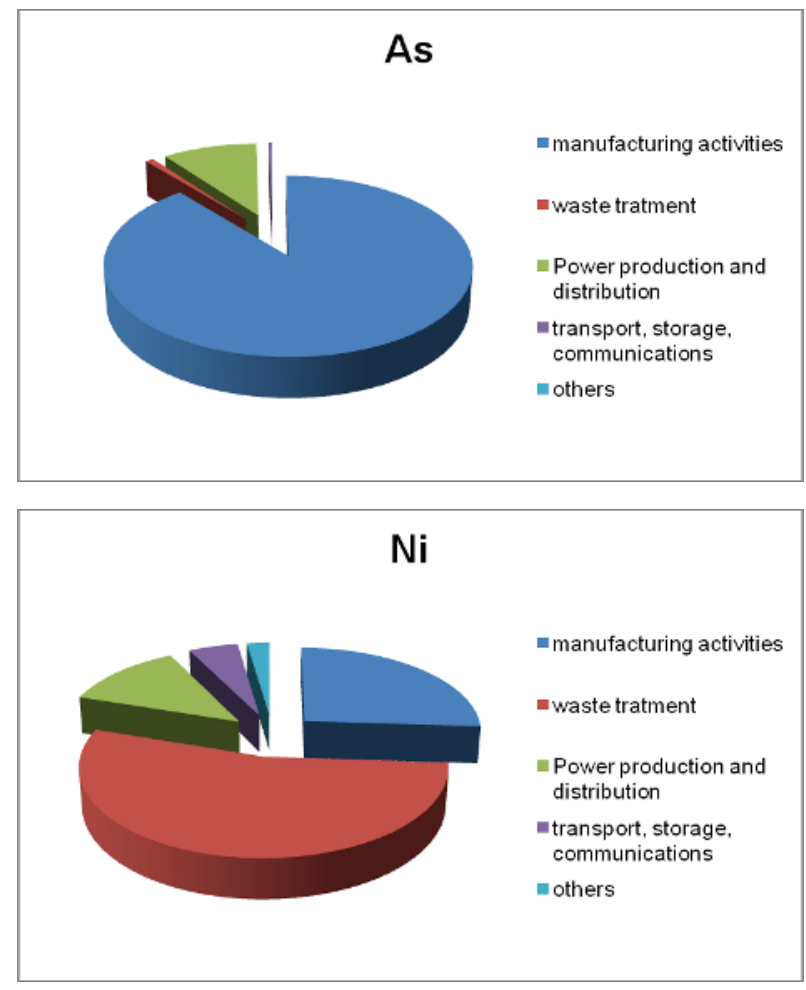

In addition, the farming sector has a considerable responsibility for cadmium emissions, while the emissions of lead from transport, storage and communications are and have been significant, especially in the past.

The figures show the quantity of emissions of cadmium, lead, arsenic and nickel in 2007.

\section{Air concentrations in Italy and in Europe}

The Directive 2004/107/EC (European Parliament, 2004) sets a target value for arsenic in ambient air concentration of $6 \mathrm{ng} / \mathrm{m}^{3}$ to be calculated on the total content in the PM10 fraction, averaged over a calendar year. According to air quality data available at Italian level (Source: Regions, Autonomous Provinces, Regional Environmental Protection Agencies, National Research Council, National Institute for Environmental Protection and Research and National Institutes of Health) and European level (Source: Airbase) urban levels of arsenic are generally below the target value of $6 \mathrm{ng} / \mathrm{m}^{3}$ showing a range of 0,5 to $5,5 \mathrm{ng} / \mathrm{m}^{3}$. At European level urban background levels show a range of 0.5 to $3 \mathrm{ng} / \mathrm{m}^{3}$. Arsenic concentrations monitored near industrial installations may be up to one order of magnitude higher depending on the type of installation and the distance and position of the monitoring site (European Commission, 2003).

According to scientific literature and to air quality data exchanged amongst Member States in Europe, urban background levels of cadmium show a range of 0.2 to 2.5 $\mathrm{ng} / \mathrm{m}^{3}$. Cadmium concentrations near industrial installations may be higher, depending on the type of 
installation and the distance and position of the monitoring site (European Commission, 2003). According to air quality data available at Italian level (Source: Regions, Autonomous Provinces, Regional Environmental Protection Agencies, National Research Council, National Institute for Environmental Protection and Research and National Institutes of Health) and European level (Source: Airbase) urban traffic and background levels are below the target value of $5 \mathrm{ng} / \mathrm{m}^{3}$ established by the so-called Fourth Daughter Directive, the Directive 2004/107/EC (European Parliament, 2004) showing a range of 0,1 to $3,0 \mathrm{ng} / \mathrm{m}^{3}$.

According to scientific literature and to air quality data exchanged amongst Member States in Europe, urban background levels of lead in Italy are below the limit value established by Directive 99/30/EC (Council of European Union, 1999) and currently in force according to Directive 2008/50/EC (European Parliament, 2008) of $0,5 \mu \mathrm{g} / \mathrm{m}^{3}$ expressed as an average yearly concentration for the protection of human health. Lead emissions have been reduced considerably as a result of the use of unleaded gasoline. Owing to decreases in the lead content of gasoline, there has been a trend towards lower air lead values both at European and Italian levels in the last years.

Referring to nickel the Directive 2004/107/EC (European Parliament, 2004) provides a target value of 20 $\mathrm{ng} / \mathrm{m}^{3}$ for the total content in the PM10 fraction, averaged over a calendar year.. According to air quality data available at Italian level (Source: Regions, Autonomous Provinces, Regional Environmental Protection Agencies, National Institute for Environmental Protection and Research) and European level (Source: Airbase) urban levels are below the target value of $20 \mathrm{ng} / \mathrm{m}^{3}$ showing a range of 5 to $15 \mathrm{ng} / \mathrm{m}^{3}$. Nickel concentrations monitored near industrial installations may be up to one order of magnitude higher depending on the type of installation and the distance and position of the monitoring site.

\section{Atmospheric depositions in Italy and in Europe}

The European Monitoring and Evaluation Programme (EMEP) is a scientifically based and policy driven programme under the Convention on Long-range Transboundary Air Pollution for international cooperation to solve transboundary air pollution problems. In particular, one of the activity of EMEP is to collect information on modelled and measured concentrations and deposition of lead, cadmium and mercury, their transboundary transport and atmospheric load to regional seas.

The EMEP has four assigned centers that annually make available reports on, among others, the transboundary pollution of the environment due to lead, cadmium and mercury, which are considered in this paper (EMEP).

\section{Comparison of trends in Italy and in Europe}

Considering the emission trends of cadmium, lead, arsenic and nickel in Italy, there has been a decrease of emissions in the last two decades.

For the example, the emissions of cadmium, lead and nickel in 1990 from manufacturing activities were 8.2, 397 and 52.3 tons respectively, while the emissions from the same sectors were 5.2, 230 and 26.6 tons respectively in 2007 .

In addition the lead emission from the wholesale and retail trade, repair of motor vehicles, motorcycles and personal and household goods which was $807.5 \mathrm{t}$ in 1990 and $32 \mathrm{~kg}$ in 2007.

The lead emission from the transport, storage and communications sector were $373.3 \mathrm{t}$ in 1990 and $5.4 \mathrm{t}$ in 2007.

In this paper air emissions, concentrations and depositions measurements are compared considering the Italian and European situation (Pacyna et al, 2007), (Pacyna et al., 2009), (Storch et al., 2003), (EMEP).

\section{Policy strategies at global level and their effects}

The Protocol on heavy metals under the UNECE LRTAP Convention states each Party shall reduce its total annual heavy metals air emissions of each heavy metal (listed in annex I) taking effective measures, appropriate to specific circumstances.

The Protocol on Heavy Metals sets legally binding limit values for the emission of particulate of $10 \mathrm{mg} / \mathrm{m} 3$ from hazardous and medical waste incineration, which reduce emissions of heavy metals indirectly. It sets also emission limit values on the emission of mercury to 0,05 $\mathrm{mg} / \mathrm{m} 3$ from hazardous waste incineration and 0,08 $\mathrm{mg} / \mathrm{m} 3$ from municipal waste incineration (UNECE).

Considering the concerns related to the adverse effects to humans and the environment caused by lead and cadmium at global level, UNEP has started a collection of information on these two metals.

In relation to this, the final reviews of scientific information on lead and cadmium with an overview of existing and future national actions, (including legislation relevant to lead and cadmium), have been presented at the 26th GC/GMEF of UNEP in 2011. UNEP has identified three current priorities for action in connection with lead and cadmium, which are lead in paint, lead in fuels and in lead and cadmium batteries (UNEPc).

\section{Policy strategies at European level and their effects}

Several EU measures have been adopted in order to control the pollution from lead, cadmium, arsenic and nickel in the main sectors.

The poster will list the main relevant EU legislation and its goal (Directives on paints, batteries, industrial emissions, etc.)

\section{Policy strategies at Italian level and their effects}

At National level, in addition to the legislative acts to 
transpose the UE directives, the policy makers, scientists and stakeholders have started the definition of a national plan in order to reduce caused by particulate matter and heavy metals.

It will be underlined main relevant strategies adopted at Italian level and possible measures for future management of heavy metal pollution.

\section{References}

European Commission: Position paper on Lead, 1997.

European Commission: Ambient air pollution by AS, Cd and Ni compounds. Position Paper, Office For Official Publications of The European Communities, 1- 315, October 2000.

European Commission: Proposal for a Directive of the European Parliament and of the Council relating to arsenic, cadmium, mercury, nickel and polycyclic aromatic hydrocarbons in ambient air, $\operatorname{COM}(2003)$ 423 final, 2003.

European Parliament: Directive 2004/107/EC of the European Parliament and of the Council of 15 December 2004 relating to arsenic, cadmium, mercury, nickel and polycyclic aromatic hydrocarbons in ambient air, Official Journal of the European Union, L 23, 3-16, 26.1.2005.

European Parliament: Directive 2008/50/EC of the European Parliament and of the Council of 21 May 2008 on ambient air quality and cleaner air for Europe, Official Journal of the European Union, L 152,2008

European Union: Council Directive 1999/30/EC of 22 April 1999 relating to limit values for sulphur dioxide, nitrogen dioxide and oxides of nitrogen, particulate matter and lead in ambient air, Official Journal of the European Communities, L 163, 1999.
Pacyna, J. M., Pacyna, E. G., Aas, W.: Changes of emissions and atmospheric deposition of mercury, lead, and cadmium, Atmospheric Environment 43, 117-127, 2009.

Storch, V., Cabrala, M. C.-, Hagnera, C., Fesera, F., Pacyna, J., Pacyna, E., Kolb, S.: Four decades of gasoline lead emissions and control policies in Europe: a retrospective assessment, The Science of the Total Environment 311, 151-176, 2003.

ISPRA_The Institute for Environmental Protection and Research, (http://www.sinanet.isprambiente.it/it/sinanet/sstoric he)

ISTAT National Institute of Statistics (http://www3.istat.it/salastampa/comunicati/non cal endario/20100202 00/).

UNEP, chemicals branch, DTIE. Final review of scientific information on cadmium. December 2010a.

UNEP, chemicals branch, DTIE. Final review of scientific information on lead. December 2010b.

UNEP_Lead and Cadmium_Priorities for actions (http://www.unep.org/hazardoussubstances/LeadCa dmium/PrioritiesforAction/tabid/6171/Default.aspx)

Pacyna, E. G.., Pacyna, J. M., Fudalac, J.,. StrzeleckaJastrzabc, E, Hlawiczkac, S., Panasiukd, D., Nittere, S., Preggere, T., Pfeiffere, H., Friedrich, R.: Current and future emissions of selected heavy metals to the atmosphere from anthropogenic sources in Europe.Atmospheric Environment 2007; 4:185578566.

UNECE Protocol on heavy metals (http://www.unece.org/fileadmin/DAM/env/lrtap/ full\%20text/1998. Heavy.Metals.e.pdf).

EMEP_ European Monitoring and Evaluation Programme (http://www.emep.int/). 